\title{
A Sudanese Male with Jaccoud's Arthropathy; Case Report
}

\author{
Sara Hamza Abushama ${ }^{1}$, Fatima Magzoub Mohamed Khatieb ${ }^{1,2}$, Leena AA Mohammed ${ }^{3}$, \\ Shaima N Elgenaid ${ }^{3}$, Mohammed Elmujtba Adam Essa ${ }^{4,5,6 *}$, Ziryab Imad Taha ${ }^{7,4}$, Ebtihal hassan \\ merghani musa ${ }^{7}$, Abdelkareem A Ahmed ${ }^{4,8}$ and Hassan Ahmed Abdullah ${ }^{1,9}$ \\ ${ }^{1}$ Department of Rheumatology, Sudan Medical Specialization Board, Sudan
}

${ }^{2}$ Department of Medicine, Almughtaribeen University, Sudan

${ }^{3}$ Faculty of Medicine, University of Khartoum, Sudan

${ }^{4}$ Departments of Clinical Medicine, Medical and Cancer Research Institute (MCRI), Sudan

${ }^{5}$ Faculty of Medicine, Al Fashir university, Sudan

${ }^{6}$ Surgery Research Department, Sudanese Medical Research Association, Sudan

${ }^{7}$ Faculty of medicine, University of Bahri, Khartoum, Sudan

${ }^{8}$ Institute of Molecular biology, University of Nyala, Sudan

${ }^{9}$ Department of Medicine and Rheumatology, Omdurman teaching Hospital, Sudan

*Corresponding author: Mohammed Elmujtba Adam Essa, Department of Clinical Medicine, Medical and Cancer Research Institute, Nyala, Sudan

\section{ARTICLE INFO}

Received: 慧 January 19, 2021

Published: 蔧 January 25, 2021

Citation: Sara Hamza Abushama, Fatima Magzoub Mohamed Khatieb, Leena AA Mohammed, Shaima N Elgenaid, Mohammed Elmujtba Adam Essa, et al. A Sudanese Male with Jaccoud's Arthropathy; Case Report. Biomed J Sci \& Tech Res 33(2)-2021. BJSTR. MS.ID.005387.

Keywords: Jaccoud's Arthropathy; Deformities; Correctable; Joints

\section{ABSTRACT}

Jaccoud's arthropathy (JA) is a condition characterized clinically by reversible joint deformities such as ulnar deviation, swan neck, thumb subluxation and hallux valgus, along with an absence of articular erosions on a plain radiograph. This report aims to highlight the clinical presentation and medical management of JA as well as to draw attention to the disease among clinicians. We are presenting a 57-year-old male, present with a history of episodes of pain and swelling in the metacarpophalangeal, proximal and distal interphalangeal joints for 20 years associated with joint stiffness for less than half an hour during the last 15 years. Clinical examination of the hand revealed joints swelling, ulnar deviation at wrist joints and fingers, Z shape deformity of thumbs, swan neck deformity of little fingers and visible wasting of thinner muscles, although there is no tenderness or skin change and all hand deformities were correctable.

\section{Abbreviations}

JA: Jaccoud's Arthropathy, ESR: Erythrocytes Sedimentation Rate, CRP: C-Reactive Protein, RA: Rheumatoid Arthritis, Anti-CCP Antibodies: Anti-citrullinated Protein Antibodies, HCQ: Hydroxychloroquine, MCP Joint: Metacarpophalangeal, SLE: Systemic Lupus Erythematosus, ANA profile: Antinuclear Antibody, LFT: Liver Function Test, RFT: Renal Function Test

\section{Introduction}

JA is a non-erosive deforming form of arthropathy that is characterized by correctable joint deformities such as ulnar deviation, thumb subluxation and swan neck deformity [1]. These deformities are mainly a result of periarticular involvement of metacarpophalangeal and proximal interphalangeal and wristjoints [2]. The reversible nature of these deformities is due to inflammatory reactions in soft tissues such as joint capsules and tendons with no bone destruction. Jaccoud's arthropathy is associated with several 
conditions such as systematic lupus erythematosus, Rheumatic fever, certain infections like HIV and some fungal infections, neoplasm and other connective tissue diseases. its prevalence in either SLE or RF is around 5\% [1]. Jaccoud's arthropathy can also be primary without any detectable underlying aetiology [3]. The morphological similarities of jaccoud's arthropathy lesions to those of the rheumatoid arthritis was the base of many types of researches that concluded that chronic post rheumatic jaccoud's arthropathy and rheumatoid arthritis are different clinical entities.

This was first described in 1950 By professor E. Bywater based on morphological, radiological and serological evidence [4]. there is a lack of published research evidence about the prevalence of JA in Sudan and its association with common etiological conditions such as rheumatic fever and SLE. This case report aims to draw attention to jaccoud's arthropathy among clinicians in developing countries.

\section{Case Presentation}

In August 2019, a 57 years old married male, a retired banker who is known to be diabetic for the past 10 years presented to the clinic with pain and deformities in both hands. He gave a history of recurrent episodes of pain and swelling in the metacarpophalangeal, proximal and distal interphalangeal, and wrist joints for the previous 20 years. the patient has also reported experiencing morning stiffness that lasted for less than 30 minutes along with neck and shoulder pains. In the past 15 years, the patient noticed marked changes in the shape and mobility of his hands to an extent that affected his daily activities. Recently the patient started to complain about new pain in the ankles and groin area. The previously mentioned symptoms were not associated with any form of skin rashes, oral or genital ulcers, hair loss, muscle pain, chest pain, shortness of breath, abdominal and central and peripheral nervous system symptoms. The patient's past medical history was significant for recurrent attacks of tonsillitis associated with joints pain when he was young.

His family history was unremarkable. At the time of presentation, the patient was on Amaryl $4 \mathrm{mg}$, proton pump inhibitor, prednisolone $5 \mathrm{mg}$ and calcicare dietary supplement. On examination, the patient looked unwell, his blood pressure was $120 \backslash 70$. Cardiovascular examination revealed murmur in the apex radiating to the axilla. The examination findings of the respiratory, abdominal and nervous systems were normal. Hand examination had detected bilateral MCP joints swelling, ulnar deviation at wrist joints and fingers, $\mathrm{Z}$ shape deformity of thumbs, swan neck deformity of little fingers and visible wasting of thinner muscles. However, there were no tenderness as well as skin and nail changes. All the previously mentioned hand deformities were correctable. Radiological examination of the hands showed ulnar deviation that is more prominent in the metacarpophalangeal joints and marked joint subluxation in both thumbs.

Chest X-ray was normal. Echocardiography was performed and it showed signs of mitral regurgitation. Laboratory investigations requested and their results are shown in (Table 1). Consequently, Methotrexate $12.5 \mathrm{mg}$ and Folic acid $5 \mathrm{mg}$ were prescribed in addition to his ongoing medications. Patient now on well condition and regular follow up despite of presence the correctable joint deformities (Figures 1-4).

Table 1: Showing laboratory results of the patient.

\begin{tabular}{|c|c|c|}
\hline Test & Result & Reference Values \\
\hline Heamoglobin & $12.1 \mathrm{~g} \backslash \mathrm{dl}$ & $13.8-17.2 \mathrm{~g} / \mathrm{dl}$ \\
\hline $\begin{array}{c}\text { Mean corpuscular volume } \\
\text { (MCV) }\end{array}$ & $90 \mathrm{fL}$ & $80-100 \mathrm{fL}$ \\
\hline $\begin{array}{c}\text { white blood cells (WBCs) } \\
\text { differential count) }\end{array}$ & $4500-11000 \times 109 / \mathrm{L}$ \\
\hline $\begin{array}{c}\text { Erythrocyte sedimentation } \\
\text { rate (ESR }\end{array}$ & $50 \mathrm{~mm} / \mathrm{hr}$ & $<20 \mathrm{~mm} / \mathrm{hr}$ \\
\hline CRP & $21 \mathrm{mg} / \mathrm{L}$ & $<2 \mathrm{mg} / \mathrm{L}$ \\
\hline Rheumatoid factor (RF) & $>100 \mathrm{IU} / \mathrm{ml}$ & $<14 \mathrm{IU} / \mathrm{ml}$ \\
\hline Anti CCP Antibodies & $192.8 \mathrm{U} / \mathrm{ml}$ & $<20 \mathrm{U} / \mathrm{ml}$ \\
\hline antinuclear antibody (ANA) & Negative & - \\
\hline Liver Function Test (LFT) & Normal & - \\
\hline Renal function Test (RFT) & Normal & - \\
\hline Urine Analysis & Normal & - \\
\hline
\end{tabular}

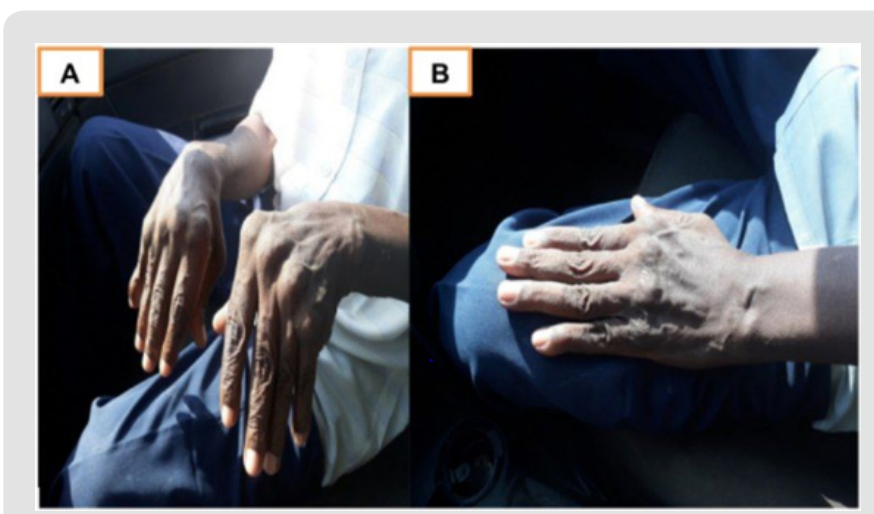

Figure 1: (A) hands showing ulnar deviation of Metacarpophalangeal joints of both hands with swelling, (B) Hand shows correctable joint deformity.

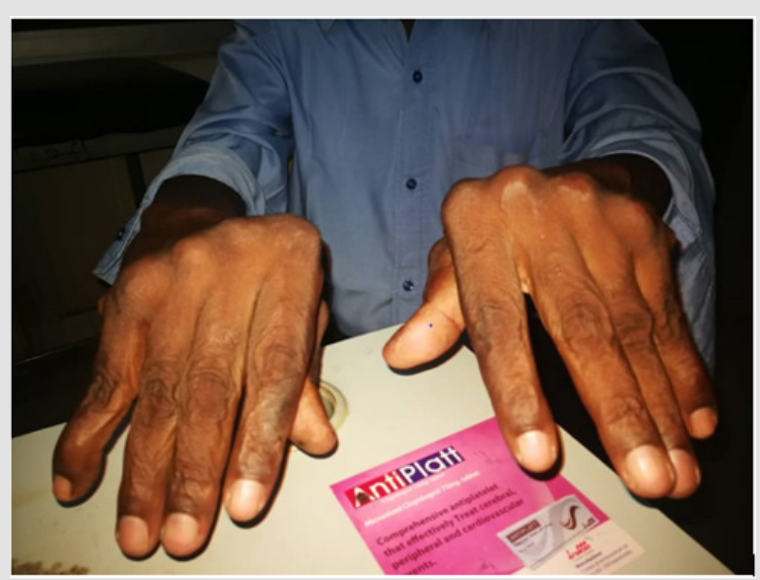

Figure 2: showing swan neck deformity on the little finger of both hands. 


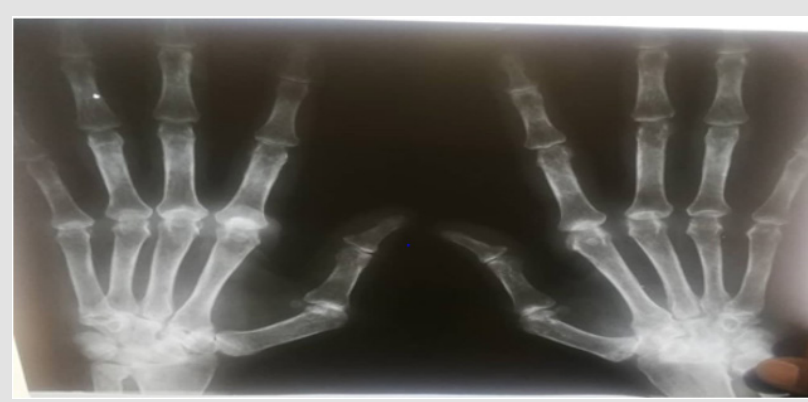

Figure 3: the figure shows the ulnar deviation in the MCP joints and thumbs sublaxation with apparent soft tissue swelling and signs of osteopenia.

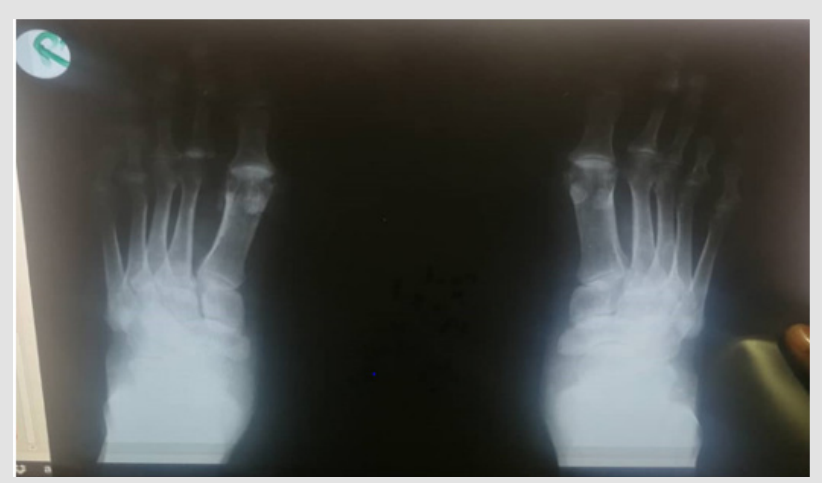

Figure 4: showing ulnar deviation in the metatarso phalangeal joints.

\section{Discussion}

Jaccouds arthropathy is strongly associated with a history of recurrent Rheumatic fever, Eric Bywater described [5], cardinal features for the diagnosis of jaccouds arthropathy that can be summarized as follows: 1: history recurrent severe attacks of Rheumatic fever, 2: delayed recovery and stiffness of MCP joints. 3: Correctable ulnar deviation, 4: normal ESR, 5: capsular fibrosis. 6: Tendon crepitus may be elicited. The patient's past history of recurrent attacks of rheumatic fever and the evidence of valvular lesions in this case is highly suggestive that the jaccoud's arthropathy is a result of rheumatic fever. A similar case was reported by Nagaraja Moorthy as a chronic post rheumatic fever arthropathy with reducible joints deformities [5]. The pathogenesis of jaccoud's arthropathy includes mainly fibrosis and degenerative changes that are more evident in the MCP joints. These changes include thickening of the joints capsule. The main histopathological change is fibrin deposition in joint capsule [6].

The differential diagnosis for this case also includes rheumatoid arthritis, SLE and hypermobility syndrome. Regarding the patient serological profile, the high anti- CCP antibodies and rheumatoid factor are also suggestive of a possible diagnosis of rheumatoid arthritis, but the absence of bone erosions and the reversible nature of the deformities are cardinal features of Jaccoud's arthropathy. A previous study has shown positive rheumatoid factors in $47.9 \%$ of patients diagnosed with jaccouds arthropathy and $12.5 \%$ of them had positive anti CCP antibodies profile [7]. It is not uncommon that rheumatoid arthritis and chronic post-rheumatic arthritis can coexist in the same patient (4), in this case the most likely diagnosis is that the patient's already existing jaccoud's arthropathy due to previous rheumatic heart disease was exacerbated by recent rheumatoid arthritis and this is further supported by the high inflammatory profile (high CRP and ESR).

There is no specific treatment for jaccoud's arthropathy as the treatment is mainly supportive, the mainstay of treatment is non-steroidal anti-inflammatory drugs, low dose steroids and antimalarial drugs (1), In this case, the patient was advised to continue using HCQ 200, and prednisolone, and methotrexate 12.5 $\mathrm{mg}$ and folic acid $5 \mathrm{mg}$ were also prescribed.

\section{Conclusion}

In this case, the patient was diagnosed with jaccoud's arthritis that is most likely due to the previous recurrent attacks of rheumatic fever based on the symptoms and radiological examination of hands and foot joints. The patient's case was further superimposed by recent rheumatoid arthritis that was evident in the high titer of rheumatoid factor, anti-CCP antibodies, CRP and ESR. The treatment was mainly supportive and methotrexate was prescribed for the rheumatoid manifestations. Further follow up is required to assess the progression of RA symptoms.

\section{References}

1. Santiago MB (2011) Jaccoud's arthropathy. Best Pract Res Clin Rheumatol 25(5): 715-725.

2. Jiang W, Pisetsky DS (2008) Expression of high mobility group protein 1 in the sera of patients and mice with systemic lupus erythematosus. Ann Rheum Dis 67(5): 727-728.

3. Sivas F, Aydoğ Ș, Pekin Y, Özoran K (2005) Idiopathic Jaccoud's arthropathy. APLAR J Rheumatol 8(1): 60-62.

4. Whitley RJ (1986) The New England Journal of Medicine Downloaded from nejm.org at UNIVERSITY OF LIVERPOOL on July 21, 2014. For personal use only. No other uses without permission. From the NEJM Archive. Copyright (c) 2009 Massachusetts Medical Society. All rights reserved. New Engl J Med 314(3):144-149.

5. Moorthy N, Ananthakrishna R (2019) Chronic postrheumatic fever arthropathy. European journal of rheumatology 6(3): 163-164.

6. Girgis FL, Popple AW, Bruckner FE (1978) Jaccoud's arthropathy. A case report and necropsy study. Jaccoud's arthropathy pp. 561-565.

7. Galvão V, Atta AM, Sousa Atta ML, Motta M, Dourado S, et al. (2009) Profile of autoantibodies in Jaccoud's arthropathy. Jt Bone Spine 76(4): 356-360. 
ISSN: 2574-1241

DOI: 10.26717/BJSTR.2021.33.005387

Mohammed Elmujtba Adam Essa. Biomed J Sci \& Tech Res

(C) (P) This work is licensed under Creative

Submission Link: https://biomedres.us/submit-manuscript.php

$\begin{array}{ll}\text { BIOMEDICAL } & \text { Assets of Publishing with us } \\ \text { RESEARCHES } & \text { - Global archiving of articles } \\ & \text { - Immediate, unrestricted online access } \\ & \text { - Rigorous Peer Review Process } \\ \end{array}$

